\section{THE SCIENCE COMMITTEE OF THE}

93ritish ettediral Assariation.

\section{AN INVESTIGA'IION INTO THE CIRCULA'TION THROUGH 'THE LUNGS. \\ BY}

S. W. F. UNDERHILL, M.A., M.B., B.Ch.Oxon., SENIOR DEMONSTILATOR OF PHYSIOLOGY, ST. BARTHOLOMEW'S HOSPITAL.

[Preliminary Report.]

INTRODUCTION.

THE importance of the pulmonary circulation is seen in the serious effects which ensue when it is interfered with in any way; this interference may be a consequence of diserse of some part of the blood vascular system itself, or may result from conditions which are present locally in the lungs or pleural cavities, thus directly affecting the pulmonary system. In the first group may be cited pulmonary embolism; in the second, pueumonia, pleural effusions, etc.

It was thought that the adaptability of the pulmonary circulation could be tested by imitating in animals, as far as is pussible, the condition of embolism of one main branch of the pulmonary artery as it occurs in man. Any conclusions reached might throw a new light on the circulation in the luugs during collapse or consolidation.

In man a large pulmonary embolus frequently causes sudden death, apparently from cardiac failure; or the symptoms may be prolonged for some hours before death eusues; or fiually recovery may occur. Apart from the heart failure, the symptoms are ascribed to insutticient oxygenation of the blood, with its consequent effects on the central nervous system and the heart itself.

\section{Part I.-Ligature of One Main Puluonary Branch} in Animals.

This condition of a large embolus was imitated, as far as possible, by ligature of one pu monary artery.

The animals used were cats: in some ether was the anaesthetic throughout; in others the preliminary opera. tive procedures were done under ether, and later urethane was substituted for it. Usually the chest was opened in the mid-line, both pleural cavities being exposed; the pericardium was also slit up. In some of the later experiments, however, in which the chest was closed again, only the left pleura was opened by cutting through a few costal cartiluges on this side; the left pulmonary artery was then reached by a small incision through the pericardium over it.

The carotid blood pressure was recorded in the usual way, and the pulmonary by means of the four-way cannula introduced by Sir E. Sliarpey Schafer. This is inserted into the right ventricle and tied in by a purse-string suture. The cannula proper projects through the pulmonary valves into the stem of the pulmonary artery. The whole instrument and its connexions are filled with a $3 \frac{1}{2}$ per cent. sodium citrate solution, and the pressure recorded by a manometer containing the same fluid. If a piston recorder is connected to the top of the manometer tubing the pressure can be recorded graphically.

Natural respirations were recorcled by a thread from the upper abdominal wall to a lever writing on the drum, and artificial ventilations by means of a bellows recorder, connected to a by-pass on the tube between the pump and the tracheal cannula.

In the experiments on cardiac output a glass cardiometer was used, connected with a piston recorder. The saturation of the blood with oxygen was estimated in a 1 c.cm. Barcroft differential blood-gas apparatus. The left branch of the pulmonary artery was that ligatured as it is the more superficial and can be easily reached.

\section{A.}

The general effects of ligature of the left pulmonary artery were studied in animals with the chest open under artificial ventilation.

The immediate effects are surprisingly few. There is no alteration in the carotid blood pressure (except sometirres an oscillation from mechanical interference with the heart when the ligature is pulled taut). There is no alteration in the rate of the heart, in its output, nor in its state of dilatation. The only noteworthy result is a rise in the pulmonary blood pressure; this is immediate and varies in amount in each case from 25 to 60 per cent. usually about 40 per cent. - of the original pressure in the pulmonary artery.

The later effects depend partly on the amount of venti. lation the animal is receiving. A slow rise in the carotid blood pressure indicates deficient oxygenation, and can be compensated by increasing the ventilation; thereafter the pressure remains steady or shoivs $\dot{a}$ continuous fall as the experiment proceeds.

The pulmonary blood pressure remains at about the same level for a varying time ( 25 to 40 minutes); it then shows a gradual fall, which is usually not so marked as the accompanying fall in the carotid blood pressure; sometimes, however, the pulmonary falls more than the carotid pressure (relatively). It is possible this signifies a further dilatation of the pulmonary arterioles.

If the ventilation is insufficient, the initial rise of pulmonary blood pressure may be followed by a further rise together with the rise in carotid pressure, both then falling when the ventilation is increased.

EXPERIMENT A.-Cat: Ether: Chest Open : Artificial Ventilation. Ligature of Left Pulmonary Artery: its Effect on Carotid and Pilmonary Bl:od Pressures.

\begin{tabular}{|c|c|c|c|}
\hline 'Time. & Remarks. & $\begin{array}{c}\text { Carotid } \\
\text { Blood } \\
\text { Pressure in } \\
\text { mm. Hg. }\end{array}$ & $\begin{array}{c}\text { Pulmonary } \\
\text { Blood } \\
\text { Pressure in } \\
\text { mm. Hg. }{ }^{*}\end{array}$ \\
\hline \multirow[t]{2}{*}{$\underset{3.0}{\text { p.m. }}$} & - & 73 & 18.5 \\
\hline & Left pulmonary artery ligated & 72 & 26.0 \\
\hline 3.1 & Ventilation increased to $1 \frac{1}{2}$ times & 74 & 27.0 \\
\hline 3.2 & Increase in ventilation only & 67 & 25.0 \\
\hline 3.11 & Ventilation doubled & 60 & 23.5 \\
\hline 3.34 & - & 64 & 21.0 \\
\hline 3.47 & $\longrightarrow$ & 64 & 20.5 \\
\hline 3.48 & \multirow{2}{*}{$\begin{array}{l}\text { Ligature unloosed. Ventilation } \\
\text { reduced to normal }\end{array}$} & 60 & 18.5 \\
\hline 3.51 & & 70 & 17.0 \\
\hline
\end{tabular}

Experiments were performed to control all the above results. The output of the heart, which was unaltered when the ligature was applied, increased markedly to an injection of gum saline intravenously, as did its state of dilatation; at the same time the rate of beat increased.

EXPERIment B.-Cat: Ether : Chest Open: Artificial.Ventilation: Heart in Cardiometer. Ligature of Left Pulmonary Artery. its Effect on the Output of the Heart.

(The ventilation was the same throughout.)

\begin{tabular}{|c|c|c|c|c|}
\hline Time. & Remarks. & $\begin{array}{l}\text { Output of } \\
\text { Left Ven- } \\
\text { tricle per } \\
\text { Beat in } \\
\text { c.cm. }\end{array}$ & $\begin{array}{c}\text { Carotid } \\
\text { B ood } \\
\text { Pressure } \\
\text { in mm.Hg. }\end{array}$ & $\begin{array}{c}\text { Pulse } \\
\text { Rate } \\
\text { per } \\
\text { Minute. }\end{array}$ \\
\hline $\begin{array}{l}\text { p.m. } \\
12.51\end{array}$ & $\longrightarrow$ & 1.5 & 92 & 192 \\
\hline 12.52 & Left pulmonary artery & 1.5 & 92 & 192 \\
\hline 12.53 & & 1.5 & 88 & 198 \\
\hline 12.55 & - & 1.5 & 86 & 192 \\
\hline 12.58 & - & 1.4 & 86 & 192 \\
\hline & $\begin{array}{c}25 \text { c.cn. gum saliue injected } \\
\text { intravenously; heart } \\
\text { dilated }\end{array}$ & 1.85 & 92 & 210 \\
\hline 12.59 & & 1.8 & 84 & 210 \\
\hline
\end{tabular}

The effects of alterations in ventilation on the circulation were carefully studied. It was found that increasing or decreasing the ventilation, within normal limits, had no effect on the rate of the heart, or its output, and very little effect on either the carotid of the pulmonary blood pressure. 
DXPERnRET O.-Gat : Ether : Chest Open : Artificial Ventilation: Heurt in Cardiometer: Effect of Alterations in Ventilation on Pulse Rate asd Carotid Blood Pressure.

(The ontpat remainod constant throughout.)

\begin{tabular}{lllll|c|c}
\hline \multicolumn{3}{c|}{ Ventilation. } & & $\begin{array}{c}\text { Pulse Rate } \\
\text { por Minute. }\end{array}$ & $\begin{array}{c}\text { Carotid Blood } \\
\text { Pressure } \\
\text { in mm. Hg. }\end{array}$ \\
\hline Normal... & $\ldots$ & $\ldots$ & $\ldots$ & $\ldots$ & 192 & 87 \\
Increased $\times 2$ & $\ldots$ & $\ldots$ & $\ldots$ & $\ldots$ & 198 & 80 \\
Diminished to t & $\ldots$ & $\ldots$ & $\ldots$ & 186 & 85 \\
Diminished to t & $\ldots$ & $\ldots$ & $\ldots$ & 186 & 86 \\
\hline
\end{tabular}

On the other hand, excessive ventilation had a mechanical effect in causing a small rise in pulmonary pressure and a fall in carotid pressure, while the reverse occurred to diminished ventilation. Apart from the mechanical effect, the result of alterations in ventilation depended on the previous amount of ventilation; when the latter was normal there was (within limits) no ohunge of blood pressure; but if the ventilation bad been insufficient and the pressures were rising, incressing it led to a coincident fall in both. It was shown that the increase in ventilation in experiments with the left pulmonary artery tied, necessary to keep the carotid blood pressure steady, was within the normal limits, and had only a trifling effect on the blood pressures in a control experiment.

FXPERIMrgNT D.-Cat : Ether : Chest $O_{1}$ en : Artificial Ventilations Effect of Alterations of Ventilation on Carotid and Pulmonary Blood Pressures.

\begin{tabular}{|c|c|c|c|}
\hline Fime. & Ventilation. & $\begin{array}{c}\text { Carotid } \\
\text { Blood } \\
\text { Pressure in } \\
\text { mm. Hg. }\end{array}$ & $\begin{array}{c}\text { Pulmonary } \\
\text { Blood } \\
\text { Pressure in } \\
\text { mm. Hg. }\end{array}$ \\
\hline & Normal & 69 & 17.0 \\
\hline Zero & Increased by 18 times & & \\
\hline $1 \mathrm{~min}$. & 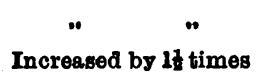 & 68 & 16.5 \\
\hline $\min$. & $n$ & 68 & 15.0 \\
\hline $8 "$ & & 60 & 14.0 \\
\hline 41 & Normal & $\infty$ & 14.0 \\
\hline 4 & Normal & 68 & 15.0 \\
\hline B & $\begin{array}{l}\text { Normal } \\
\text { Diminished to } 8\end{array}$ & 68 & 26.6 \\
\hline 6 min. & $\ddot{m} \ddot{3}$ & 69 & 16.5 \\
\hline " & $\begin{array}{c}" \ddot{ } \\
\text { Normal }\end{array}$ & 73 & 17.0 \\
\hline $10 \mathrm{~min}$. & Normal & 73 & 28.5 \\
\hline
\end{tabular}

Occasionally the carotid blood pressure showed a fall on ligature of the left pulmonary artery; this was only seen in animals in poor condition, and indicated that the heart was unequal to the strain put upon it.

It is obvious from these results that the healthy right ventricle can send out the same quantity of blood in a given time through one lung only as it was sending out previously through both, and thus maintains the carotid blood pressure at the same level. The increase in pressure in the pulmonary artery was never more than 60 per cent. of the original pressure; hence there must be a dilatation of the right pulmonary arterio'es and capillaries at the same time as the rise in pressure, if twice the original rolume of blood is to flow thr ugh the one lung in a given time. The velocity of blood flow will therefore be increased but not doubled.

It was of interest to investigate the saturation of the blood with oxygen under these conditions. It was found that it was quite possible for the blood to be 90 to 95 per cent. saturated, provided sufficient ventilation was being given. If the blood was more nnsaturated than this, increasing the ventilation would improve its saturation. The increase necessary was within the normal limits- that is, it cansed not more than a trifling alteration of carotid blood pressure.

The fact of the pulse rate remaining unaltered on ligature of the left pulmonary artery, althoush the pulmonary pressure rose, suggests that the right ventricle is not provided with a mechanism comparable to that on the left side, which causes slowing of the heart with rise of blood pressure. At any rate, it is clear that the healthy heart shows no difficulty in meeting the extra strain put upon it.

In some experiments the ligature was released after a variable time; the carotid blood pressure was generally unaffected by this procedure unless there was mechanical interference with the heart. In a few cases, when the ligature was taut for a short time only, the reverse effect to that seen on tying was observed. In the case of the pulmonary blood pressure, however, there was always a fall; which was usually to the same, or nearly the same, figure as obtained before the ligature was tied. If, however, while the ligature was on the pulmonary blood pressure had fallen, there was still a further fall on its removal. This fall was smaller relatively than the rise on ligation (see Experiment A above)

The blood saturation improved somewhat when the ligature was removed, but not so much as might have been expected. The saturation was 80 per cent. to 90 per cent. (with n rmal, not increased, ventilation). This presumably indicate 8 damage to the left lung, or deterioration of the animal during the course of the experiment.

B.

A further series of experiments was performed, in which, after the left pulmonary branch had been ligated, the chest was closed and the artificial ventilation withdrawn, the animal being allowed to breathe naturally.

The effect of closure of the chest on the blood pressures was first determined in a case with an intact pulmonary system. It was found that both were slightly lower with the animal breathing naturally than they had been under artificial ventilation with the chest open: if now with the chest closed, artificial ventilation was put on, the pul. monary blood pressure showed a small rise, and on opening the cliest again there was a further rise in this, accompanied by a rise in carotid blood pressure. These effects can be explained as due to the pressure inside the chest: with natural respiration this is negative, leading to dilata. tion of pulmonary arterioles, and possibly other blood vessels ; with positive artificial ventilaiion these arterioles are compressed, causing a small rise of pressure.

EXPERIMENT E.-Cat: Ether: Effect of Closure of Chest on Blood Pressures.

\begin{tabular}{|c|c|c|}
\hline Remarks. & $\begin{array}{c}\text { Carotid } \\
\text { Blood } \\
\text { Pressure } \\
\text { in mm. Hg. }\end{array}$ & $\begin{array}{c}\text { Pulmonary } \\
\text { Blood } \\
\text { Pressure } \\
\text { in mm. Hg. }\end{array}$ \\
\hline Chest open: artificial ventilation ... & 82 & 13.7 \\
\hline Chest shut : neturel respiration & 75 & 10.7 \\
\hline $\begin{array}{llll}\text { Later } & \ldots & \ldots & \ldots\end{array}$ & 80 & 11.1! \\
\hline Chest shut: artiffcial ventilation ... & 80 & 13.3 \\
\hline Ohest opened : artificial ventilation & 90 & 14.4 \\
\hline
\end{tabular}

When the left pulmonary branch has been tied and the chest closed, the blood pressures may remain steady, or show a small fall (probably due to the operative procedures). This fall tends to be recovered from, and often there is a very distinct improvement in the animal's condition after time has been allowed it to settle down.

At present the most satisfactory results have been obtained in animals which have only had a minimum of operative interference, such as the ligature of the left pulmonary artery through an opening in the left chest, by cutting through four rib cartilages, without opening the right pleural cavity at all, or the pericardium more than is necessary to enable the ligature to be put round the artery. If, on the other hand, the chest has been widely opened and a palmonary cannula also inserted, it has so far been found that the animal is unable to breathe properly when the chest has been closed. In the earlier experiments it was ascertained directly that there was a 
negative pressure in the thorax after closure of the chest, by means of a cannula communicating with the plearal cavity and connected to a water manometer. In later experiments this has been dispensed with; the lungs are blown out before the last suture is drawn taut, and, when the animal is breathing naturally, the chest is auscultated to see that air is entering the lungs.

In cases which, survive the respiratory rate is quicker than normal, usually about double, but the respirations have a tendency to be shallow. Sometimes, huwever, they are normal in rate and depth.

Animals can be kept alive for at least six hours after closure of the chest, and with the left pulmonary artery ligatured, in perfectly good condition, with a blond pressure of 90 to $100 \mathrm{~mm}$. Hg or more. The pulse rate remains fairly constant throughout or may show a slight retardation after the chest is closed.

It is of considerable interest to compare the oxygen saturation of the blood under these conditions with the results found (and previously mentioned) as obtaining in cases where the chest has not been closed and the animal has been artificially ventilated throughout. A considerably lower degree of saturation has been found, when the animal is breathing naturally; the blood is usually only 70 per cent, to 75 per cent. saturated, in spite of the increase in the respiration rate.

Investigation into this question is, howerer, still proseeding.

EXPERIMENT F 1.-Cat: Ether: Ligature of Left Pulmomary Aitery through a Small Incision through Left Thoracio Wall near Mid-line, and Closure of Chest again.

\begin{tabular}{|c|c|c|c|c|}
\hline Time. & Remarks. & $\begin{array}{c}\text { Cerotid } \\
\text { Blood } \\
\text { Pressure } \\
\text { in mm. Hg. }\end{array}$ & $\begin{array}{c}\text { Pulse } \\
\text { Rato } \\
\text { por Min. }\end{array}$ & $\begin{array}{c}\text { Respiration } \\
\text { Rate } \\
\text { per Min. }\end{array}$ \\
\hline$\underset{11.40}{\operatorname{a.m}}$ & Control observations & 100 & 198 & 32 \\
\hline 12.3. & $\begin{array}{l}\text { Chest op on: artificial } \\
\text { ventilation } \\
\text { Left pulmonary artery } \\
\text { ligated }\end{array}$ & $\begin{array}{r}100 \\
-\end{array}$ & - & - \\
\hline 12.7 & - & 108 & - & - \\
\hline 12.24 & hest now closed : natural & 85 & 132 & $48^{*}$ \\
\hline 12.45 & - & 75 & 120 & $37+$ \\
\hline 1.25 & - - & 95 & - & 34 \\
\hline 2.3 & 一 & 120 & 144 & 26 \\
\hline 3.15 & Killed by asphyxiation & 120 & 210 & 34 \\
\hline
\end{tabular}

EXPERIMENT F 2.-Cat: Ether and Urethane.*

(Experimental procedures and observations similar to $F$ 1.)

\begin{tabular}{|c|c|c|c|c|}
\hline Time. & Remarks. & $\begin{array}{c}\text { Carotid } \\
\text { Blood } \\
\text { Pressure } \\
\text { in mm. Hg. }\end{array}$ & $\begin{array}{c}\text { Pulse } \\
\text { Rate } \\
\text { per Min. }\end{array}$ & $\begin{array}{c}\text { Respiration } \\
\text { Rate } \\
\text { per Min. }\end{array}$ \\
\hline $\begin{array}{l}\text { a.m. } \\
\text { 11. } 30\end{array}$ & Control observations & 78 & 216 & 48 \\
\hline 12.0 & $\begin{array}{c}\text { Chest open; artificial } \\
\text { ventilation }\end{array}$ & 72 & 216 & - \\
\hline p m. & $\begin{array}{c}\text { Left pulmonary artery } \\
\text { ligatured }\end{array}$ & $\begin{array}{l}64 \text { rising to } \\
74 \text { in } \frac{1}{2} \text { min. }\end{array}$ & - & - \\
\hline 12.12 & $\begin{array}{c}\text { Chest closed; natural } \\
\text { respirations }\end{array}$ & 88 & 216 & $\boldsymbol{9}$ \\
\hline 1.23 & - & 85 & - & $\boldsymbol{9}$ \\
\hline 2.0 & $\longrightarrow$ & 90 & 216 & $\boldsymbol{\infty}$ \\
\hline 3.15 & - & 95 & 192 & 72 \\
\hline 4.3 & $\longrightarrow$ & 90 & 204 & 78 \\
\hline 5.42 & - & 82 & 192 & 66 \\
\hline 5.45 & Both vagi cut & 88 & - & 28 \\
\hline 5.50 & ${ }_{\text {(Killed) }}$ & 88 & - & 12 \\
\hline
\end{tabular}

* Atropine 0.016 grain given hypodermically at commencement.

\section{C.-The Condition of the Lungs.}

Post-mortem examinations of the lungs were always made, and frequently pieces taken between ligatures for section, both during the course of the experiment and at the end.

All cases showed very similar appearances. After ligature of the left pulmonary artery, and while the chest is still open (artificial ventilation), the left lung is obviously paler than the right, and also paler than it was before the ligation. Microscopic sections show an almost complete absence of blood in the capillaries and arteries, although some can still be seen in the veins. At the same time the right lung contains more blood than normal, since twice the usual quantity is flowing through it in a given time. In the case of the left lung the squeezing effect of the positive inflation, together with the stopping of the blood flow, is sufficient to force the greater part of the blood out of it.

If, now, the ligature is removed, the circulation is re. established through the left lung, but at the same time oedema occurs in the alveoli, showing that damage has been done by the stoppage of the blood flow.

When the chest has been closed and the animal has breathed naturally - the pulmonary capillaries thus being exposed to a negative intrathoracio pressure-the appearance, post mortem, of the right lung is not greatly altered from that previously described, but the left lung presents a very different picture, being full of blood and frequently congested.

Since the ligature has always been taut, post mortem, there are only two possible sources for th.s blood-the bronchial arteries or the pulmonary (and brouchial) veins. It was thought that under a negative pressure, and with expansion of the left lung to the respiratory movements, blood might be sucked back from the left auricle into the lung, producing a staguant collection of blood and so impairing the general condition.

Experiments were performed to determine between these two possibilities. If the left pulmonary veins are ligatured just before they enter the left auricle, after the left pulmonary artery has been tied, and the chest closed in the usual manner, the left lung is found intensely con. gested after death. Microscopically, a condition of engorgement is found, such as has been seen in no other cases; it is obvious, therefore, that a considerable circulation exists from the bronchial arteries, and that the blood they bring to the lung is unable to return in its entirety through the bronchial veins, a great part of it being returned normally via the pulmonary veins.

On the other hand, if all the structures going to a lobe of the left lung are tied except the veins and bronchus, that lobe remains fairly free of blood compared to the other lobe, even although the latter has its pulmonary artery ligated.

- Presumably, therefore, the blood found in the left lung post mortem after the left pulmonary artery has been tied, comes from the bronchial arteries. In most experiments there seems to be more blood in the left than in the right lung, but in a few the reverse is the case. Since the com. munication between the bronchial arteries and pulmonary system is one of capillaries only, the blood which is not returned via the bronchial veins filters through into the pulmonary capillaries under a very low pressure, which is not sufficient to force it onwards into the veins in any quantity, thus leading to congestion.

All the lungs show mucus in the bronchi to a greater or less degree, even after a previous injection of atropine subcutaneously. The right lung has shown no oedema, except in the case of an animal which has lived for about six hours; the amount present then is, howerer small and insufficient to cause death. As a matter of fact, this animal appeared in quite good condition when it was killed. This oedema of slow development is probably due to the fact that double the normai amount of blood is flowing through the right lung in a given time (under a pressure slightly higher than the normal).

\section{Part II.-Experiments with Right Bronchus} Obstructed.

In the second series of experiments the right bronchus was clamped or tied, and a similar set of observations made to those reported in the first series. 
Ligature of Right Bronchus.

The experiment was performed with the chest open and under artificial ventilation. There was no immediate effect on the carotid blood pressure (unless there had been mechanical interference with the heart during the operative procedures, when there was a fall); during the next few minutes, however, it showed a slow rise, which was undoubtedly anoxaemic in origin, and was usually stopped by increasing the ventilation. Sometimes, in spite of full ventilation, the rise was maintained. At other times the carotid pressure was maintained steady, but the effects of the anoxaemia were seen in the fall of pulse rate and increase in the pulse pressure, increasing the ventilation then bringing about the reverse changes.

'The pulmonary blood pressure showed a small immediate rise, which might not be maintained, or was merged in a further late rise, accompanying the carotid pressure rise; like the latter, an increase in the ventilation now caused a fall. Sometimes the pulmonary pressure rose independently of the carotid. The saturation of the blood was under 90 per cent. in these experiments, in spite of the fact that the ventilation had been increased. The small rise in pulmonary blood pressure suggests that some circulation is still occurring through the right lung, and this is confirmed by the low blood saturation.

Investigations on the effects of ligature of a bronchus on the pulmonary blood pressure and blood saturation are still proceeding.

\section{Summary and Conclusions.}

1. Ligature of the left pulmonary artery in cats (with the chest open and under artificial ventilation) causes a rise of pulmonary blood pressure of from 25 per cent. to 60 per cent.- usually about 40 per cent. There is no effect on the carotid blood pressure, pulse rate, output of the heart, or its state of dilatation.

2. The healthy heart therefore can accommodate itself without difficulty to sending the same volume of blood through one lung only in a given time, as it previously sent through both.

3. No mechanism producing slowing of the heart from rise of pulmonary blood pressure was demonstrated in these experiments.

4. If the chest is closed after the artery has been ligatured, the animal remains in good condition-in fact, frequently its condition is improved. Its respiratory rate is usually faster than normal, frequently about double, but the depth tends to be shallow.

5. The saturation of the blood after ligature is about 75 per cent.; if the artificial ventilation is increased (within normal limits), complete saturation can be obtained. This has not been the case, howerer, with animals in which the chest has been closed and the artificial ventilation discontinued; in these the saturation remains at about 70 per cent.

6. Examination of the lungs shows an increased quantity of blood in the right lung, due to twice the normal volume flowing through it in a given time. The left lung after ligature of the left pulmonary artery, under artificial ventilation, contains almost no blood, except a little in the veins; on the other hand, after the chest has been closed and the animal allowed to breathe naturally, it contains usually more blood than the right lung, exhibiting a varying degree of congestion. This blood comes from the bronchial arteries and stagnates in the pulmonary capillaries.

7. Ligature of the right bronchus (in cats with the chest open and under artificial ventilation) causes a small immediate rise in pulmonary blood pressure without affecting the carotid pressure.

8. The saturation of the blood has always been under 90 per cent., even when the artificial ventilation has been increased.

9. There is, therefore, presumably still a certain amonnt of circulation through the right lung under these conditions.

Investigation is still proceeding on the following points?

(a) The degree of saturation of the blood, after the left pulmonary artery has been tied and the chest closed.

(b) The effects of ligature of a bronchus on the pulmonary blood pressure and the blood saturation, since the observations in this series are as yet few.
I wish to thank Professor F. A. Bainbridge for con. tinuous help and advice during the course of these experiments.

Barcroft. The Respiratory Fr'tunct on of the Rlood (1914). Sharpey Schater: Quart. Juarn. Exper. Lhysiol, 12, 133; Ibid.., 12, 395.

\section{A NOTE ON THE EARLY RECOGNITION AND} CORRECTIVE TREATMENT OF OCCIPI'IOPOS'TERIOR PRESENTA'TIONS.

BY

R. C. BUIST, M.A., M.D.Dundee,

CLINICAL LECTURER IN THE UNIVERSITY OF ST. ANDREWG,

IT does not seem to be generally known that for those who have the opportunity to see a case of occipito-posterior presentation in the week before delivery or very early in labour, it is possible to make an exact diannosis by external palpation and to correct it by external methods. In the application of the routine four hand-grips in palpation the bilateral grip shows the lateral lie of the trunk, and, in addition, the extra facility with which the limbs may be telt may awaken the suspicion of possibly posterior occiput. The exact recognition is then frequently practicable by a modification of the two-handed pelvic grip. The symmetrically laid hands sink directly backwards from the line of the pubic bones, and from the relatively greater sink on one side the oblique diameter in which the head tends to lie may be defined. When the diameter and the side on which the trunk lies are the same, both right or both left, the posteriority is definite. In the next step the hands are again symmetrica ly placed, but, instead of sinking back from the pubic level, they are withdrawn upwards. The attitude of the head, the extent of its flexion, is shown by the inclination, to the horizontal line of the pubic brim, of the line in which the hands cease to feel the head, the occipito-mental base.

The external treatment is simple and usually successful. $A$ binder is laid under the patient and two towel pads are prepared. The first is rolled to about the thickness of a forearm, the second is folded to a flat pad 6 or 7 inches square. The rolled pad is pinned to the binder in such a position that when the binder is firmly secured the pad will lie close in front of the anterior superior iliac spine behind and parallel to the trunk. The flat pad is pinned so as to lie on the limbs, pressing them backwards. It is sometimes useful to roll the patient to the side opposite the trunk and by hand bring the trunk as far as may be over to that side. The binder is then pulled firmly home. If the patient is actually in labour nothing more may be needed, but if she is still on foot the binder should be steadied by thigh-bands and the correctness of its position frequently supervised. When in bed the patient should be encouraged to lie on the side opposite to the trunk, but her comfort is a prior consideration.

The success I have experienced from this method of treatment is so high that the usually described method of correction by manual reposition from the vagina is now rarely needed. The actual manipulations in this latter replacement are perhaps not personally familiar to some of the writers who describe it. In a very recently issued diagram the operator is shown using his right hand internally and, with obvious gaucherie, the left hand externally in a right occipito-posterior presentation. The correct method of standing on the patient's left side and using the left hand internally is shown by Munro Kerr in Operative Midwifery. For a left occipito-posterior case the stand should be on the right and the right hand used internally, when the patient is in the dorsal position.

Aocording to the Deutsche medizinische Wochenschrift the venereal disease clinics in Berlin were attended by 6,454 persons in 1918, by 22,338 in 1919 , and by 23,819 in 1920 . The venereal disease clinics throughout Germany were attended by 27,000 persons in 1918, and by 95,000 in 1919 .

IN December, 1921, the Société de Médécine de Paris will award the Duparcque Prize of 3,000 francs to the author of the best essay in French on the methods of determining the functional activity of the liver, and their applications to medicine, surgery, and obstetrics. The Guillon Prize of 300 trancs will be awarded by the same society for the best essay on diseases of the urinary tract. 